\title{
Voltage Profile and THD Distortion of Residential Network with High Penetration of Plug-in Electrical Vehicles
}

\author{
Sara Deilami, Student Member, IEEE, Amir S. Masoum, Student Member, IEEE, \\ Paul S. Moses, Student Member, IEEE, and Mohammad A. S. Masoum, Senior Member, IEEE
}

\begin{abstract}
This paper analyzes the potential impacts of Plug-in Electric Vehicles (PEVs) on the voltage profile, losses, power quality and daily load curve of low voltage residential network. PEVs are soon expected to grow in popularity as a low emission mode of transport compared to conventional petroleum based vehicles. Utilities are concerned about the potential detrimental impacts that multiple domestic PEV charging may have on network equipment (e.g., transformer and cable stresses). To address these issues, two charging regimes including uncoordinated (random) and coordinated (uniformly distribution) are considered. Based on harmonic analysis of a typical 19 bus low voltage $(415 \mathrm{~V})$ residential network, different charging scenarios over a 24 hour period are compared considering voltage deviations, system losses, transformer overloading and harmonic distortions. Simulation results are used to highlight the advantages of the coordinated uniformly distributed charging of PEV in residential systems.
\end{abstract}

Index Terms--Smart grid, residential system, PEV charging, voltage profile, losses, coordinated charging and harmonics.

\section{INTRODUCTION}

Plug-in Electrical Vehicles (PEVs) are becoming more practical and popular in developing countries over conventional fuel-based vehicles as an efficient and more environmental friendly mode of transport. Smart appliances such as PEV will soon be able to "talk" to the grid and decide how best to operate and automatically schedule their activity at strategic times based on available generation.

So far there has been significant research in integrating customer demand side management into smart grids to improve the system load profile and reduce peak demand [19]. However, there are growing concerns and issues about the relatively high ratings, nonlinearities and charging regimes associated with PEVs, as well as their impacts on overall daily load patterns for residential systems [1]. An unexpected number of simultaneous PEV charger loads during the peak hours may alter the overall residential daily load curve, detriment power quality, increase system losses and cause

S. Deilami, P.S. Moses and M.A.S. Masoum are with the Department of Electrical and Computer Engineering, Curtin University of Technology, Perth, Australia_(s.deilami@postgrad.curtin.edu.au;paul.s.moses@gmail.com; m.masoum@curtin.edu.au). A.S. Masoum is with Transmission Maintenance Delivery, Western Power, WA (amir.sherkatmasoum@westernpower.com.au). voltage fluctuations and overloading problems. Voltage deviations may cause reliability problems that should not be underestimated in order to avoid malfunctioning of electric appliances [10].

In order to investigate the above-mentioned potential problems, this paper aims to simulate a typical low voltage residential system with nonlinear PEV loads in the harmonic domain. The impacts of different charging regimes (random and uniformly distributed), charging periods (peak and offpeak) and PEV penetration (low, moderate and high) on performance and power quality of the grid considering load variations over a 24 hour period will be studied.

\section{HARMONIC POWER FLOW}

For the harmonic power-flow calculation, a decoupled approach is employed. This is justified due to the acceptable accuracy of the proposed decoupled harmonic power flow (DHPF) and the fact that industrial distribution systems consist of a large number of linear and nonlinear loads that cause convergence and memory storage problems if the harmonic couplings are considered [11].

At harmonic frequencies, the system is modeled as a combination of passive elements and harmonic current sources. The related admittance matrix is modified according to the harmonic frequency [12], [13], [14]. The general model of linear load as resistance in parallel with a reactance is utilized [14]. Nonlinear loads are modeled as current sources that inject harmonic current into the system. The fundamental and the $h^{\text {th }}$ harmonic current of the nonlinear load installed at bus $i$ with real power $P$ and reactive power $Q$ are modeled as

$I_{i}^{l}=\left[\left(P_{i}+j Q_{i}\right) / V_{i}^{1}\right]^{*}$

$I_{i}^{h}=C(h) I_{i}^{l}$

Where $C(h)$ is the ratio of the $h^{\text {th }}$ harmonic current to its fundamental. The harmonic voltages are computed by solving the following load-flow equation:

$Y^{h} V^{h}=I^{h}$.

The voltage at bus is defined as

$\left|V_{i}\right|=\left(\sum_{h=1}^{H}\left|V_{i}^{h}\right|^{2}\right)^{1 / 2}$

and the total harmonic distortions of voltage (THDv) and current $\left(T H D_{i}\right)$ are 


$$
\begin{aligned}
& T H D_{v}=\left[\left(\sum_{h \neq 1}^{H}\left|V_{i}^{h}\right|^{2}\right)^{1 / 2} /\left|V_{i}^{l}\right|\right] \times 100 \% \\
& T H D_{i}=\left[\left(\sum_{h \neq 1}^{H}\left|I_{i}^{h}\right|^{2}\right)^{1 / 2} /\left|I_{i}^{l}\right|\right] \times 100 \%
\end{aligned}
$$

Where $\mathrm{H}=49$ is the highest harmonic order considered.

\section{The Low Voltage Distorted Residential System}

In this paper, the argument is made for taking advantage of smart grids to more effectively manage loads to mitigate the impact of harmonic distortion in low voltage residential systems. For example, charging PEVs could be dispersed in their scheduling to avoid too many charger loads coming online at one time to pollute the electrical system. Such operation can cause unacceptable bus voltage distortions and increase harmonic losses. The focus is on uniform distribution of PEV charging to improve voltage profile, reduce losses, avoid line overloading and limit harmonic stresses on the residential distribution transformers.

\section{A. System under Study}

A typical low voltage 19 bus $415 \mathrm{~V}$ residential system is considered and modified to include different levels of PEV penetration (Fig. 1). A 100kVA transformer feeds the residential grid. Different $\mathrm{PEV}$ penetration levels (low, moderate and high) and three charging periods (5pm-8am, $5 \mathrm{pm}-12 \mathrm{pm}$, and $5 \mathrm{pm}-7 \mathrm{pm}$ ) with the possibility of one to two PEV loads per house (each rated at $4 \mathrm{~kW}$ each) are considered.

The typical daily load curve of Fig. 2 will be used and the system parameters are provided in the Appendix.

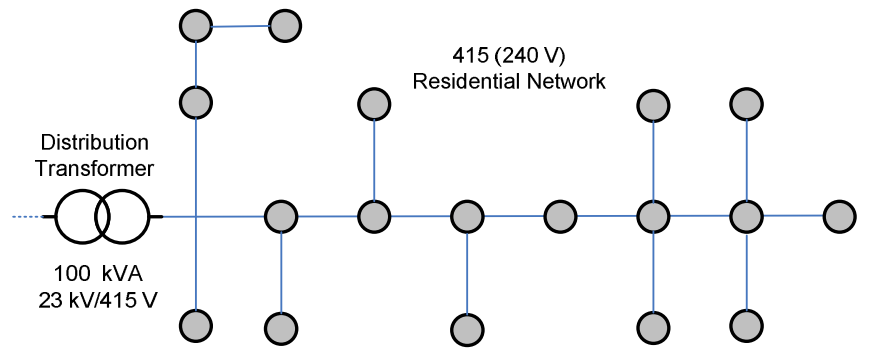

Fig.1. The typical 19-bus $415 \mathrm{~V}$ residential system.

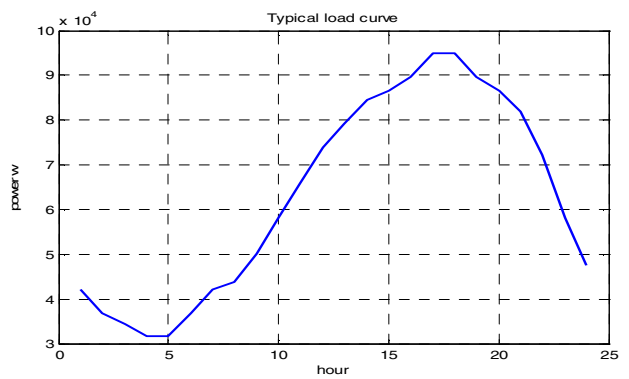

Fig.2. Typical daily load curve

\section{B. Plug-in Electric Vehicles (PEVs)}

Plug-in electric vehicles are becoming popular as a low emission mode of transport which will dramatically increase their presence in residential and distribution systems in the near future. Smart grids provide the unique opportunity to manage not only the energy storage options, but also address power quality impacts presented by the highly nonlinear charging circuitry employed for PEVs.

In this paper, different (low, moderate and high) penetrations of PEVs are placed at various locations along the low voltage $415 \mathrm{~V}$ residential distribution feeder of Figure 1 to investigate the detrimental impacts of uncoordinated charging. Based on [10], the assumed maximum operating power level per PEV charger at a customer's premise is $4 \mathrm{~kW}$. PEVs will be charged at any place where the standard outlet is present. In this article, they are assumed to be charged at home for two hours. Typical harmonic current content and waveform of PEV chargers obtained from [10] are shown in Table I and Fig. 3, respectively.

TABLE I

TYPICAL LINE CURRENT HARMONIC CONTENT OF A TYPICAL ELECTRIC VEHICLE CHARGER [10]

\begin{tabular}{|c|c|c|}
\hline $\begin{array}{c}\text { Harmonic } \\
\text { order } \\
h\end{array}$ & $\begin{array}{c}\text { Harmonic } \\
\text { magnitude } \\
{[\%]}\end{array}$ & $\begin{array}{c}\text { Harmonic } \\
\text { phase angle } \\
\text { [degrees] }\end{array}$ \\
\hline 1 & 100 & -26 \\
\hline 5 & 25 & -94 \\
\hline 7 & 17 & -67 \\
\hline 11 & 9 & -67 \\
\hline 13 & 5 & -46 \\
\hline$T H D_{i}($ Eq. 5$)$ & \multicolumn{2}{|c|}{$31.9 \%$} \\
\hline
\end{tabular}

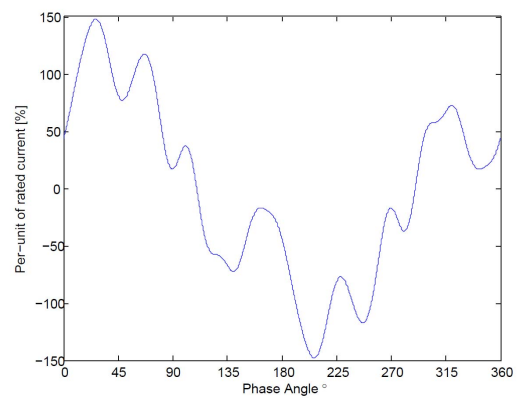

Fig.3. Waveform of input current for PEV charger (Table I)

\section{Proposed Coordinated PEV Charging Scheme}

This paper simulates and examines two PEV charging schemes: uncoordinated (random charging) and coordinated (uniformly distribution charging over the projected charging period).

\section{A. Uncoordinated Random PEV Charging}

In this scheme, it is assumed that customers don't have the required information to schedule their PEV chargers. Therefore, they will randomly charge vehicles as they arrive home during the evening (peak) hours. For the analysis of this paper, three levels of PEV penetrations (low, moderate and high) will be considered. Each PEV is assumed to be rated at 4 $\mathrm{kW}$ and designed for constant current charging over a two hours period.

\section{B. Coordinated Uniformly Distribution PEV Charging}

A relatively simple alternative to the undesired random PEV charging is considered where the PEV charging is uniformly distributed over the designated charging period. The idea is educate and encourage the consumers to smartly distribute their charging periods during the off-peak hours. 


\section{Charging Zones}

Three charging zones (periods) are considered:

- Green zone: $5 \mathrm{pm}$ to $8 \mathrm{am}$.

- Yellow zone: $5 \mathrm{pm}$ to $12 \mathrm{pm}$.

- Red zone: $5 \mathrm{pm}$ to $7 \mathrm{pm}$ (peak residential hours).

\section{Simulation Results}

In order to investigate the impact of uncoordinated and coordinated PEV charging on the voltage profile, losses and power quality of the grid, the following operating conditions and cases are considered:

- Three charging zones: green (5pm-8am), yellow (5pm$12 \mathrm{pm}$ ) and red (during the peak load; $5 \mathrm{pm}-7 \mathrm{pm}$ ).

- Two charging schemes: uncoordinated random charging of PEVs and uniform distribution of PEV charging over the allowable charging periods.

- Three PEV penetration levels: $30 \%, 60 \%$ and $100 \%$.

Case 1: Low PEV Penetration (30\%)

The impact of uncoordinated and coordinated PEV charging on the residential system (Fig. 1) with a low PEV penetration of $30 \%$ (6 PEVs) are studied based on the DHPF algorithm of Section II. The maximum number of electric vehicles is assumed to be $18 \mathrm{PEVs}$.

PEVs are randomly placed for uncoordinated charging over the 19 buses. First bus is assumed to be the swing bus and PEVs can be connected to each of the remaining 18 buses. The selection of nodes and number of PEVs connected to each bus will definitely affect the calculations and simulation results. In order to have a precise comparison, the same selected random PEV locations are used for both uncoordinated and coordinated charging. Therefore, PEVs in uncoordinated PEV charging scenario are determined to be connected to the same buses in coordinated PEV charging and ultimately, the impact of PEV placement can be ignored.

Simulation results are provided in Table II. The current THD at the worst bus and the total power losses are shown in Figure 4.

\section{Case 2: Moderate PEV Penetration (60\%)}

Simulations are performed for a moderate PEV penetration of 60\% (11 PEVs). Simulation results are provided in Table II. Figures 5a and 5b show THDi (at the worst bus) and the system power losses, respectively.

\section{Case 3: High PEV Penetration (100\%)}

Simulation results for high penetration of PEVs (18 units) are provided in Table II and figures $6 \mathrm{a}$ and $6 \mathrm{~b}$.

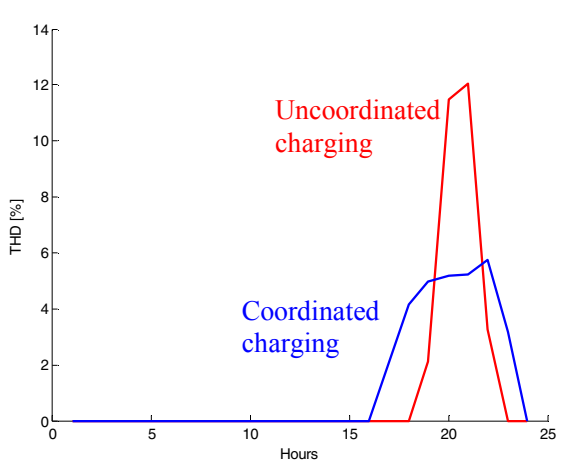

Figure 4(a). Case 1- THD voltage distortion at the worst bus (node 15) for uncoordinated $(5 \mathrm{pm}-12 \mathrm{pm})$ and coordinated $(5 \mathrm{pm}-12 \mathrm{pm})$ low penetration of PEV charging

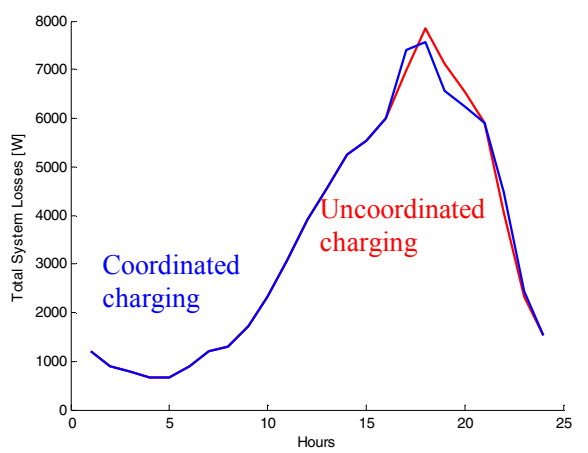

Figure 4(b). Case1- Total power losses for uncoordinated (5pm-12pm) and coordinated (5pm-12pm) low penetration of PEV charging

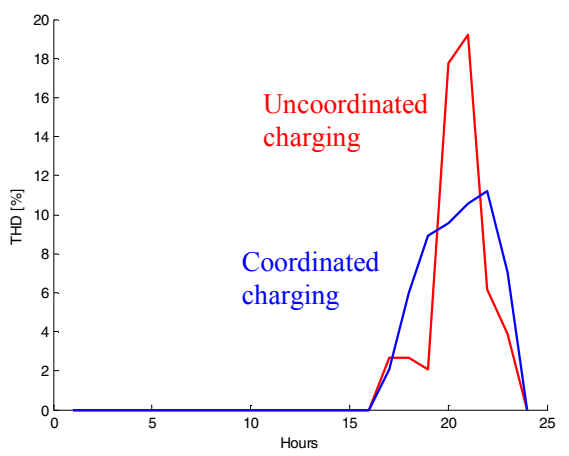

Figure 5(a). Case 1- THD voltage distortion at the worst bus (node 15) for uncoordinated $(5 \mathrm{pm}-12 \mathrm{pm})$ and coordinated $(5 \mathrm{pm}-12 \mathrm{pm})$ moderate penetration of PEV charging

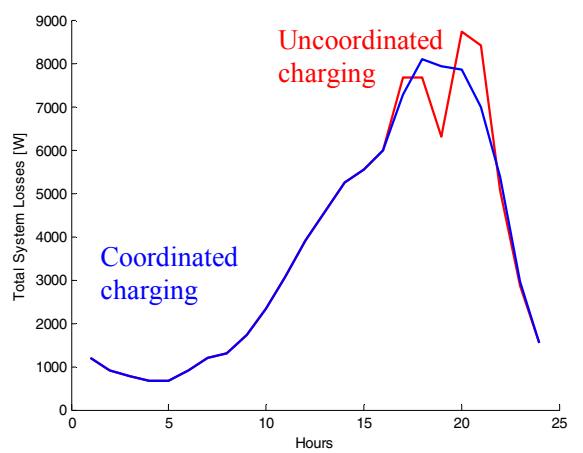

Figure 5(b). Case 2- Total power losses for uncoordinated (5pm-12pm) and coordinated $(5 \mathrm{pm}-12 \mathrm{pm})$ moderate penetration of PEV charging 


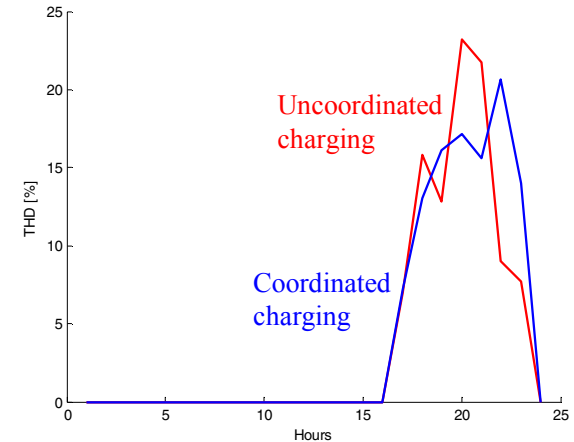

Figure 6(a). Case 2- THD voltage distortion at the worst bus (node10) for uncoordinated $(5 \mathrm{pm}-12 \mathrm{pm})$ and coordinated $(5 \mathrm{pm}-12 \mathrm{pm})$ high penetration of PEV charging

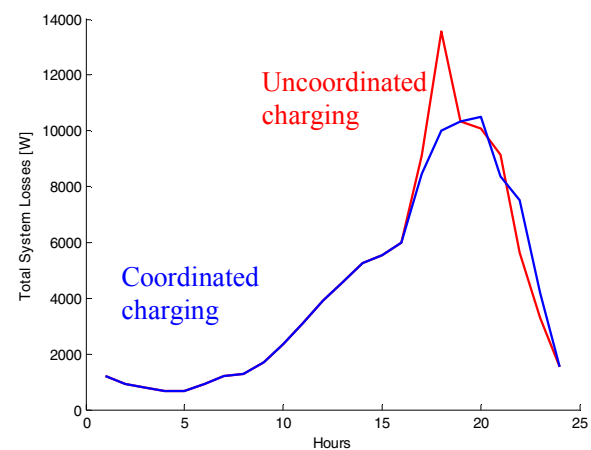

Figure 6(b). Case 3- Total power losses for uncoordinated (5pm-12pm) and coordinated $(5 \mathrm{pm}-12 \mathrm{pm})$ high penetration of PEV charging

\section{ANALYSIS}

In this section, simulation results (Figs. 7-10) for high penetration of PEVs $(100 \%)$ are presented and compared for two charging scenarios; uncoordinated charging during peak load (red zone: $5 \mathrm{pm}-7 \mathrm{pm}$ ) and coordinated charging during the off-peak (green zone: $5 \mathrm{pm}-8 \mathrm{am}$ ). The justifications for deploying different time zones for the two charging approaches are as follows:

- In a realistic scenario, most uncoordinated charging will occur within the narrower red time zone $(5 \mathrm{pm}-7 \mathrm{pm})$ upon the arrival of PEV owners from work (worst case), or, after some fixed delay into the evening. In this situation the system peak rises sharply and broadens due to much of the PEV charging loads coinciding with normal system load peaks. Severe voltage deviations, THD distortion, power losses and significant increase in transformer loading can occur as shown in Table II.

- The main purpose of coordinated charging is to force offpeak hours PEV charging to overcome these detrimental effects. The best coordinated case occurs if charging actions are uniformly distributed over the widest green time zone (5pm-8am). For this scenario, the impact on the system peak is lessened. Therefore, compared to the uncoordinated case, a significant improvement in smart grid performance could be achieved.

According to Figures 7, with uncoordinated charging the total system losses can be increased up to $500 \%$ during peak load while the proposed coordinated charging uniformly distributes PEV loads over the off-peak hours (5pm to 8am) and results in considerable lower loss levels. A similar situation occurs with the THD levels (Figure 8) which are improved from $45 \%$ (uncoordinated charging) to about $15 \%$ for coordinated charging.

Coordinated charging can also improve the voltage profile as demonstrated in Figure 9 where the unacceptable voltage levels of $0.75 \mathrm{pu}$ at the worst bus in partially compensated to about $0.83 \mathrm{pu}$. Figures 10 (a) and (b) show the impacts of PEV charging on the overall daily load curve. Both charging schemes show system overloading during peak hours; however, coordinated charging has less detrimental impacts.

Simulation results of Figs. 7-10 call for a more sophisticated charging approach which is beyond the scope of this paper.

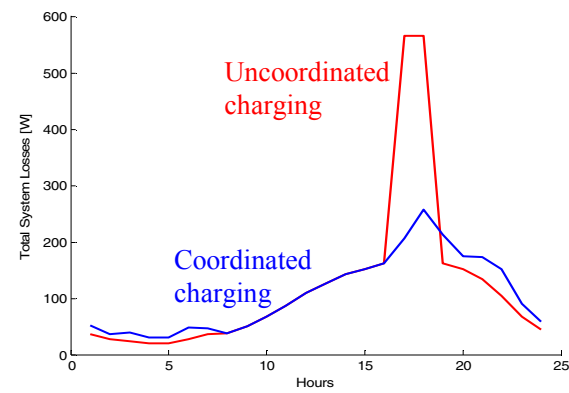

Figure 7. Comparison of total power losses for $100 \%$ penetration of PEV charging; uncoordinated charging $(5 \mathrm{pm}-7 \mathrm{pm})$ versus coordinated uniformly distributed charging $(5 \mathrm{pm}-8 \mathrm{am})$

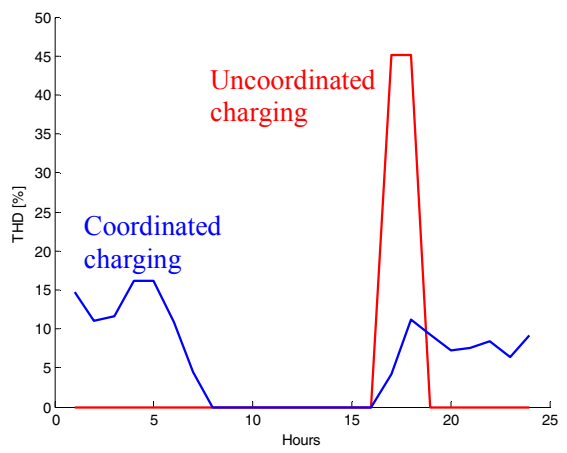

Figure 8. Comparison of THD voltage distortion for $100 \%$ penetration of PEV charging at the worst bus (node 10); uncoordinated charging $(5 \mathrm{pm}-7 \mathrm{pm})$ versus uniformly distributed charging $(5 \mathrm{pm}-8 \mathrm{am})$

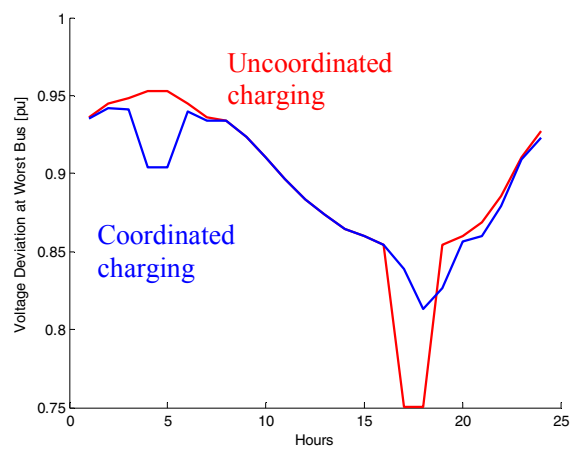

Figure 9. Comparison of maximum voltage deviation of the worst bus (node 10) for $100 \%$ penetration of PEV charging; uncoordinated charging $(5 \mathrm{pm}-$ $7 \mathrm{pm})$ versus uniformly distributed charging (5pm-8am) 


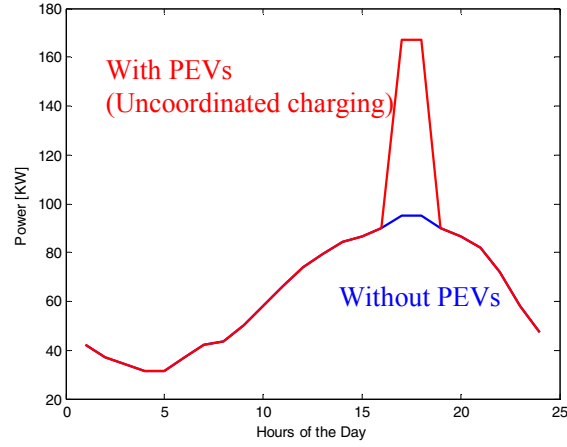

(a)

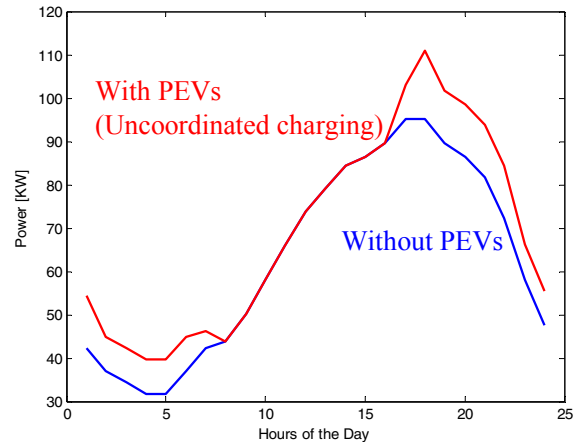

(b)

Figure 10. Daily load curves without any PEV and with a high penetration of PEVs using uncoordinated (a) and coordinated (b) charging

TABLE II

IMPACT OF RANDOM UNCOORDINATED CHARGING VERSUS UNIFORMLY DISTRIBUTED PEV CHARGING ON THE POWER QUALITY OF RESIDENTIAL SYSTEM (FIGURE1)

\begin{tabular}{|c|c|c|c|c|c|c|c|c|}
\hline \multirow{2}{*}{$\begin{array}{c}\text { ChaRgING } \\
\text { PERIODS }\end{array}$} & \multicolumn{4}{|c|}{ Uncoordinated (Random) PEV Charging } & \multicolumn{4}{|c|}{ Coordinated (Uniformly Distributed) PEV Charging } \\
\hline & $\begin{array}{c}\Delta \text { loss }^{*} \\
{[\%]}\end{array}$ & $\begin{array}{c}\Delta \mathrm{V}^{* *} \\
{[\%]}\end{array}$ & $\begin{array}{c}\mathrm{I}_{\mathrm{MAX}} * * * \\
{[\mathrm{pu}]}\end{array}$ & $\begin{array}{c}\text { THDV } \\
{[\%]}\end{array}$ & $\begin{array}{c}\Delta \text { loss }^{*} \\
{[\%]}\end{array}$ & $\begin{array}{c}\Delta \mathrm{V}^{* *} \\
{[\%]}\end{array}$ & $\begin{array}{c}\mathrm{I}_{\mathrm{MAX}} * * * \\
{[\mathrm{pu}]}\end{array}$ & $\begin{array}{c}\text { THDV } \\
{[\%]}\end{array}$ \\
\hline \multicolumn{9}{|c|}{ CASE 1: LOW PEV PENETRATION (30\%), NUMBER OF PEVS=6 (FIGS. 4A-4B) } \\
\hline $5 \mathrm{pm}-8 \mathrm{am}$ & 7.1666 & 10.8145 & 1.0702 & 9.7662 & 7.3508 & 11.2460 & 1.1512 & 5.2128 \\
\hline $5 \mathrm{pm}-12 \mathrm{pm}$ & 6.6904 & 10.8145 & 1.1686 & 12.0450 & 7.3508 & 11.2916 & 1.1512 & 5.7563 \\
\hline $5 \mathrm{pm}-7 \mathrm{pm}$ (peak) & 8.0123 & 11.9189 & 1.3200 & 12.3718 & 8.0123 & 11.9189 & 1.3200 & 12.3718 \\
\hline \multicolumn{9}{|c|}{ CASE 2 : Moderate PEV PENETRATION (60\%), NUMBER OF PEVS= 11 (FIGS. 5A-5B) } \\
\hline $5 \mathrm{pm}-8 \mathrm{am}$ & 6.9080 & 10.4433 & 1.0868 & 14.1605 & 7.2484 & 10.9326 & 1.1500 & 11.0006 \\
\hline $5 \mathrm{pm}-12 \mathrm{pm}$ & 7.3501 & 11.4729 & 1.2983 & 19.1976 & 7.5608 & 11.5479 & 1.1936 & 11.1792 \\
\hline $5 \mathrm{pm}-7 \mathrm{pm}$ (peak) & 10.1535 & 13.4792 & 1.5574 & 23.8978 & 10.1535 & 13.4792 & 1.5574 & 23.8978 \\
\hline \multicolumn{9}{|c|}{ CASE 3: HIGH PEV PENETRATION (100\%), NUMBER OF PEVS= 18 (FIGS. 6A-6B) } \\
\hline $5 \mathrm{pm}-8 \mathrm{am}$ & 7.3358 & 10.4041 & 1.1765 & 22.4150 & 8.9731 & 12.8371 & 1.2497 & 16.1782 \\
\hline $5 \mathrm{pm}-12 \mathrm{pm}$ & 10.7188 & 19.6538 & 1.3883 & 23.2272 & 8.8261 & 13.3092 & 1.3249 & 20.6539 \\
\hline $5 \mathrm{pm}-7 \mathrm{pm}$ (peak) & 15.5038 & 20.2222 & 1.9497 & 45.1715 & 15.5038 & 20.2222 & 1.9497 & 45.1715 \\
\hline
\end{tabular}

*) Increase in system losses compared to rated losses.

**) Voltage deviation above the maximum allowable limit (e.g., 1pu) at the worst bus.

***) Maximum distribution transformer load current.

\section{CONCLUSION}

The impacts of Plug in Electrical Vehicles (PEVs) on the performance and power quality of a typical low voltage residential system have been explored through extensive simulations. The nonlinearity of PEV charging circuitry including low order harmonic current injections has been considered using a decoupled harmonic power flow algorithm. Three charging zones (green, yellow and red), two charging schemes (uncoordinated and coordinated) and three PEV penetration levels (low, moderate and high) are considered. Main conclusions are:

- Penetration of PEVs, charging regime and charging zones (periods) have major impacts on system losses (Fig. 7), THD voltage distortion (Fig. 8), voltage profile (Fig. 9) and the overall daily load curve (Fig. 10).

- Random charging of the PEV batteries can result in expensive power losses, unacceptable voltage violations, extensive line loadings and THD voltage levels above the recommended limits of the IEEE-519std.

- Based on the results of this paper, uniformly distributed PEV charging can considerably improve system performance; however, it will still result in overvoltages and high THD conditions at some buses during the peak hours. This calls for a more sophisticated charging approach which is beyond the scope of this paper.

\section{APPENDIX}

System parameters of the typical low voltage 19 bus $415 \mathrm{~V}$ residential system (Fig. 1) including load and line parameters are listed in Tables D1 and D2, respectively.

TABLE D1

LINEAR AND NONLINEAR (PEV) LOADS OF THE TYPICAL LOW VOLTAGE RESIDENTIAL SYSTEM (FIG. 1)

\begin{tabular}{|c|l|c|c|}
\hline \multicolumn{2}{|c|}{ Linear and PEV Load } & \multicolumn{2}{c|}{ Power } \\
\hline Bus & Name & $\mathrm{kW}$ & $\mathrm{kVAR}$ \\
\hline 2 to19 & Linear loads & 5 & 2.42 \\
\hline At selected buses & PEV loads & 4 & 0 \\
\hline
\end{tabular}


TABLE D2

LINE PARAMETERS OF THE TYPICAL LOW VOLTAGE RESIDENTIAL SYSTEM (FIG. 1)

\begin{tabular}{|c|c|c|c|}
\hline \multicolumn{2}{|c|}{ Line } & \multirow[b]{2}{*}{$\begin{array}{c}\text { Line resistance } \\
\mathrm{R}[\Omega]\end{array}$} & \multirow[b]{2}{*}{$\begin{array}{c}\text { Line reactance } \\
\mathrm{X}[\Omega]\end{array}$} \\
\hline $\begin{array}{l}\text { From } \\
\text { bus }\end{array}$ & $\begin{array}{l}\text { To } \\
\text { bus }\end{array}$ & & \\
\hline 1 & 2 & 0.041451 & 0.014461 \\
\hline 2 & 3 & 0.042407 & 0.018924 \\
\hline 3 & 4 & 0.044360 & 0.019795 \\
\hline 4 & 5 & 0.036915 & 0.016473 \\
\hline 5 & 6 & 0.052031 & 0.023218 \\
\hline 6 & 7 & 0.052356 & 0.023364 \\
\hline 7 & 8 & 0.000513 & 0.000195 \\
\hline 7 & 9 & 0.200244 & 0.019970 \\
\hline 7 & 10 & 1.734005 & 0.172931 \\
\hline 6 & 11 & 0.260702 & 0.025999 \\
\hline 6 & 12 & 1.360527 & 0.135684 \\
\hline 4 & 13 & 0.14023 & 0.013985 \\
\hline 3 & 14 & 0.776297 & 0.077419 \\
\hline 2 & 15 & 0.597698 & 0.059608 \\
\hline 1 & 16 & 0.142289 & 0.049642 \\
\hline 16 & 17 & 0.083711 & 0.029205 \\
\hline 17 & 18 & 0.312354 & 0.031150 \\
\hline 1 & 19 & 0.016300 & 0.006200 \\
\hline
\end{tabular}

\section{REFERENCES}

[1] M. A. S. Masoum, P. S. Moses, and S. Deilami, "Load management in smart grids considering harmonic distortion and transformer derating," in International Conference on Innovative Smart Grid Technologies (ISGT), 2010, pp. 1-7.

[2] T. F. Garrity, "Innovation and trends for future electric power systems," in Proc. PSC '09. Power Systems Conference, 10-13 March 2009, pp. $1-8$.

[3] Q. B. Dam, S. Mohagheghi, and J. Stoupis, "Intelligent demand response scheme for customer side load management," in Proc. IEEE Energy 2030 Conference ENERGY 2008, Nov. 17-18, 2008, pp. 1-7.

[4] G. Mauri, D. Moneta, and C. Bettoni, "Energy conservation and smartgrids: New challenge for multimetering infrastructures," in Proc. IEEE Bucharest PowerTech, Jun. 2009, pp. 1-7.

[5] K. Abreu, "Pge's perspective on demand response under the smart grid paradigm," in Proc. IEEE/PES Power Systems Conference and Exposition PES '09, Mar. 15-18, 2009, pp. 1-2.

[6] S. Bruno, S. Lamonaca, M. L. Scala, G. Rotondo, and U. Stecchi, "Load control through smart-metering on distribution networks," in Proc. IEEE Bucharest PowerTech, Jun. 2009, pp. 1-8.

[7] A. Chuang and C. Gellings, "Demand-side integration for customer choice through variable service subscription," in Proc. IEEE Power. Energy Society General Meeting PES '09, Jul. 26-30, 2009, pp. 1-7.

[8] L. Yanxia and J. Jiuchun, "Harmonic-study of electric vehicle chargers," in Proc. Eighth International Conference on Electrical Machines and Systems ICEMS 2005, vol. 3, 27-29 Sept. 2005, pp. 2404-2407.

[9] S. Massoud Amin and B. F. Wollenberg, "Toward a smart grid: power delivery for the 21st century," IEEE Power Energy Mag., vol. 3, no. 5, pp. 34-41, Sept.-Oct. 2005.

[10] P. T. Staats, W. M. Grady, A. Arapostathis, and R. S. Thallam, "A statistical method for predicting the net harmonic currents generated by a concentration of electric vehicle battery chargers," IEEE Transactions on Power Delivery, vol. 12, pp. 1258-1266, 1997.

[11] E. F. Fuchs and M. A. S. Masoum, Power Quality in Electrical Machines and Power Systems. New York: Academic, 2008.

[12] H.-C. Chin, "Optimal shunt capacitor allocation by fuzzy dynamic programming," Elect. Power Syst. Res., vol. 35, no. 2, pp. 133-139, 1995.

[13] D. Xia and G. T. Heydt, "Harmonic power flow studies, part I Formulation and Solution," IEEE Trans. on Power Apparatus and System, vol. 101, no. 6, pp. 1257-1265, 1982.

[14] T. S. Chung and H. C. Leung, "A genetic algorithm approach in optimal capacitor selection with harmonic distortion considerations," Int. J. Elect. Power Energy Syst., vol. 21, no. 8, pp. 561-569, 1999.

[15] Y. Baghzouz and S. Ertem, "Shunt capacitor sizing for radial distribution feeders with distorted substation voltage," IEEE Trans. Power Del., vol. 5, no. 2, pp. 650-657, Apr. 1990.
[16] E. F. Fuchs, D. Lin, and J. Martynaitis, "Measurement of three-phase transformer derating and reactive power demand under nonlinear loading conditions," IEEE Trans. Power Del., vol. 21, no. 2, pp. 665672, April 2006.

[17] E. F. Fuchs and M. A. S. Masoum, Power Quality in Electrical Machines and Power Systems. New York: Academic, 2008.

[18] T. S. Chung and H. C. Leung, "A genetic algorithm approach in optimal capacitor selection with harmonic distortion considerations," Int. J. Elect. Power Energy Syst., vol. 21, no. 8, pp. 561-569, 1999.

[19] D. Xia and G. T. Heydt, "Harmonic power flow studies, part I Formulation and Solution," IEEE Trans. on Power Apparatus andSystem, vol. 101, no. 6, pp. 1257-1265, 1982.

[20] Y. Baghzouz and S. Ertem, "Shunt capacitor sizing for radial distribution feeders with distorted substation voltage," IEEE Trans. Power Del., vol. 5, no. 2, pp. 650-657, Apr. 1990.

[21] S. H. Berisha, G. G. Karady, R. Ahmad, R. Hobbs, and D. Karner "Current harmonics generated by electric vehicle battery chargers," in Proc. International Conference on Power Electronics, Drives and Energy Systems for Industrial Growth, vol. 1, 8-11 Jan. 1996, pp. 584 589.

[22] J. A. Orr, A. E. Emanuel, and K. W. Oberg, "Current harmonics generated by a cluster of electric vehicle battery chargers," IEEE Trans. Power App. Syst., no. 3, pp. 691-700, March 1982.

[23] E. W. C. Lo, D. Sustanto, and C. C. Fok, "Harmonic load flow study for electric vehicle chargers," in Proc. IEEE 1999 International Conference on Power Electronics and Drive Systems PEDS '99, vol. 1, 27-29 July 1999, pp. 495-500.

Sara Deilami (S'09) received her B.S. degree in Electrical EngineeringElectronics in 2000 from Islamic Azad University, Tehran, Iran. She was awarded a Curtin University Postgraduate Scholarship (CUPS) in 2010 is presently working towards a Master degree in Electrical Engineering at Curtin University of Technology, Perth, Australia. Her interests include optimal dispatch of shunt capacitors and LTC, harmonics, power quality and protection and renewable energy systems. She has eight years of industry experience as an engineer working in consultant companies.

Amir S. Masoum received his B.Eng. degree in Electrical Engineering in 2009 from the University of Western Australia (UWA), Perth, Australia. $\mathrm{He}$ is currently a Contract Networks Engineer at the Transmission Maintenance Delivery, Western Power, Kewdale, WA, 6105. Amir also has two years of industry experience as a testing technician at Magellan Power, O'Connor, WA, Australia. His main interests are control and energy management of renewable energy resources and power system.

Paul S. Moses (S'09) received his B.Eng. (1st Class Hons.) and B.Sc. degrees in Electrical Engineering and Physics in 2006 from Curtin University of Technology, Perth, Australia. He received the W J Smith Memorial Prize for Best Electrical Engineering Honors Thesis and the Don Watts Prize from the Faculty of Engineering for the most innovative research project. He was awarded an Australian Postgraduate Award scholarship in 2009 and is presently working towards a $\mathrm{PhD}$ degree in Electrical Engineering at Curtin University of Technology. Since 2007, he has also been working as a research scientist for the Defence Science and Technology Organisation (DSTO) in the Department of Defence, Australia, and is presently part of their Maritime Platforms Division, Propulsion and Energy Systems Group. His research interests include nonlinear electromagnetic phenomena, power quality, smart grids and protection.

Mohammad A. S. Masoum (SM'05) received his B.S., M.S. and Ph.D. degrees in Electrical and Computer Engineering in 1983, 1985, and 1991, respectively, from the University of Colorado at Boulder, USA. Dr. Masoum's research interests include optimization, power quality and stability of power systems/electric machines and distributed generation. Currently, he is an Associate Professor and the discipline leader for Power System Engineering at the Electrical and Computer Engineering Department, Curtin University of Technology, Perth, Australia. He is a senior member of IEEE. 